\title{
SHEAR STRENGTH OF CONDUCTIVE ADHESIVE JOINTS ON RIGID AND FLEXIBLE SUBSTRATES DEPENDING ON ADHESIVE QUANTITY
}

\author{
Martin Hirman ${ }^{*}$ _ Frantisek Steiner ${ }^{*}, * *$
}

\begin{abstract}
This article deals with the impact of electrically conductive adhesive quantity on the shear strength of joints glued by adhesives "EPO-TEK@ H20S" and "MG 8331S" on three types of substrates (FR-4, MELINEX®ST504, DuPont ${ }^{\text {TM }}$ Pyralux(AC). These joints were made by gluing chip resistors 1206, 0805 and 0603, with two curing profiles for each adhesive. Different thicknesses of stencil and reductions in the size of the hole in stencils were used for this experiment. These differences have an effect on the quantity of conductive adhesives which must be used on the samples. Samples were measured after the curing process by using a shear strength test applied by the device LabTest 3.030. This article presents the effects of different curing profiles, various types of substrates, and different quantities of adhesives on the mechanical strength of the joint.
\end{abstract}

K e y w o r d s: electrically conductive adhesive, flexible substrate, shear strength, quantity of adhesives, factor analysis, glued joint

\section{INTRODUCTION}

Electrically conductive adhesives are one of the possible substitutes for soldering when connecting components with substrates. In the past, lead solder alloys were almost always used, but currently lead solder alloys are prohibited by the European Directive RoHS (Restriction of Hazardous Substances) [1] and WEEE (Waste Electrical and Electronic Equipment) [2]. As a result, lead free solder alloys or electrically conductive adhesives are used. Creating conductive connections of components with substrates is the main purpose of electrically conductive adhesives. At present, this purpose for these adhesives is viable and advisable, especially for the connection of components onto flexible substrates. Flexible electronics and wearable electronics are currently being investigated and, indeed, designed (eg [3]). These modern electronic devices are commonly very small, portable (between different environments) and have short life-cycles. For these electronics devices, it is necessary to ensure a reliable, flexible and cheap joint with good mechanical and electrical properties.

\section{THEORY}

The properties required of joints for flexible electronic devices, as mentioned in the introduction, can be provided by electrically conductive adhesives. These adhesives usually have a lower curing temperature than the melting point of solder alloys. One of the main advantage of adhesives used on flexible substrates is their own flexibility. The main disadvantages of adhesives are higher price and hygroscopicity. The possibility of applying a smaller amount of adhesive without a significant degradation of desirable properties was the main hypothesis and motivation for performing the experiment described in this article. Electrically conductive adhesives have been researched by many teams of researchers, but these teams were focused on electrical properties - especially electric resistance and noise $(e g[4,5])$; the mechanical properties of electrically conductive adhesive joints have not commonly been researched.

The influence of the surface finish of rigid PCBs on electric resistance [6], and on reliability [7] of glued joints has been looked into, but again the influence of electrically conductive adhesive quantity on the mechanical reliability of glued joint on flexible substrate has not been researched.

The mechanical properties of soldered joints, especially their mechanical shear strength, have been well researched, and the results published in many articles (eg [8]), but the corresponding properties of electrically conductive adhesives are looked at only in a very few articles $(e g[9])$. The mechanical shear strength of conductive adhesives is an important topic which it is necessary to investigate.

In the past, the mechanical shear strength of glued joints in comparison to soldered joints on rigid substrates have been studied [10]. The influence of solder alloy quantity on mechanical shear strength have also been looked at (eg [11]) but the influence of electrically conductive

\footnotetext{
University of West Bohemia, Faculty of Electrical Engineering, Univerzitni 8, 30614 Pilsen, Czech Republic ${ }^{*}$ Department of Technologies and Measurement, ${ }^{* *}$ Regional Innovation Centre for Electrical Engineering (RICE), hirmanm@ket.zcu.cz, steiner@ket.zcu.cz
} 


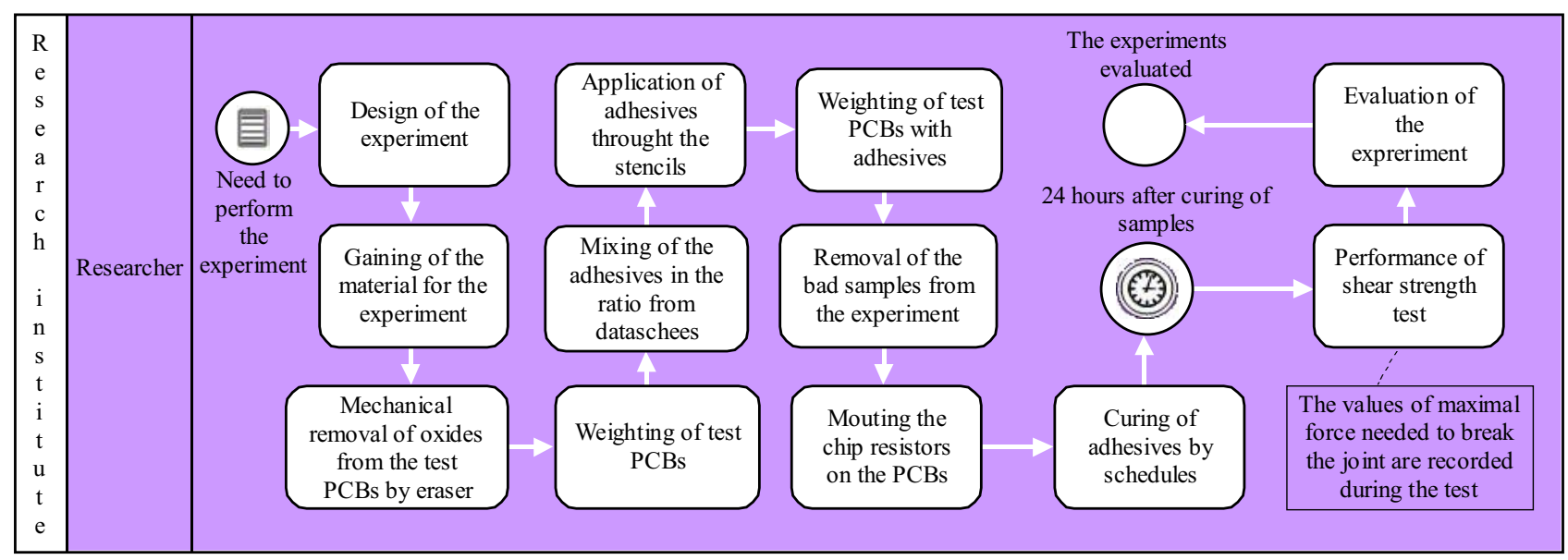

Fig. 1. Description of the experiment

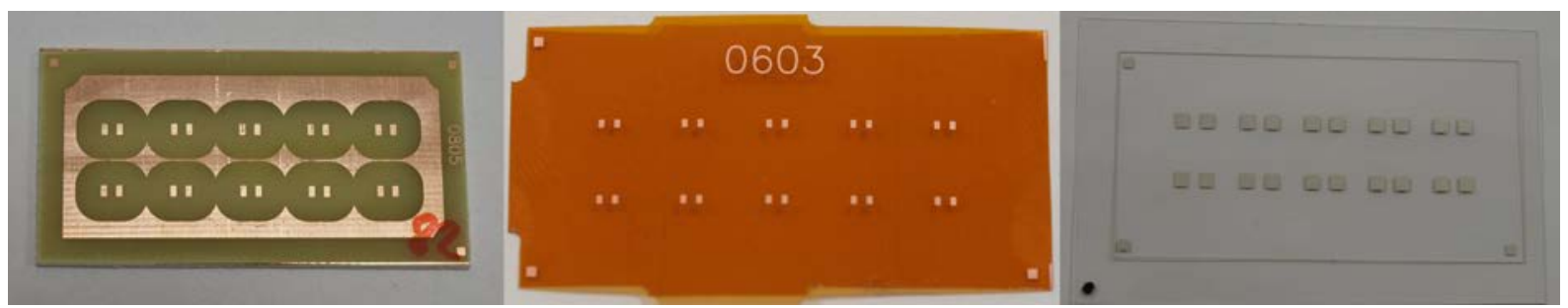

Fig. 2. The sample of RPCB Cu (left), FPCB Cu (center) and FPCB Ag (right)

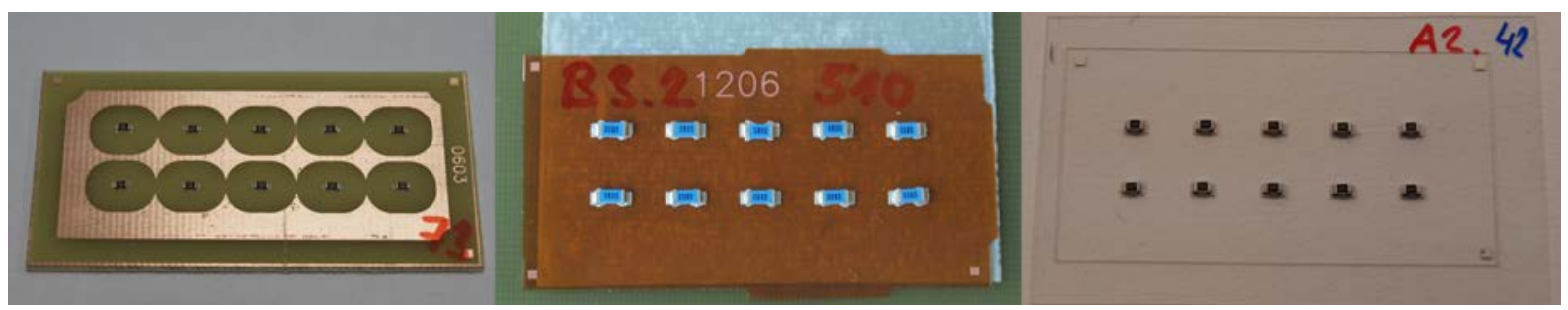

Fig. 3. The RPCB Cu with placed 0805 (left), FPCB Cu with placed 1206 (center) and FPCB Ag with placed 0805 (right) chip resistors

adhesive quantity on mechanical shear strength on flexible substrates, specifically, has not been investigated. Due to the high price of electrically conductive adhesives, research into the influence of electrically conductive adhesive quantity on the shear strength of electrically conductive adhesive joints is important. Saving a small amount of adhesive on one joint could reduce the production costs of an item significantly. This has now been investigated by our team of researchers, and the results described in this article.

\section{EXPERIMENTS}

The description of the experiment, as a process, was created by using methodology BPMN 2.0 [12] (Business Process Model and Notation). Such process descriptions can be seen in many articles (eg [13]). The process is shown in Fig. 1.

Three different types of substrate were used for the experiment. The first type was rigid printed circuit board
FR-4 with a clean copper surface only (hereinafter referred to as "RPCB Cu"). The second type was the flexible printed circuit board DuPont ${ }^{\mathrm{TM}}$ Pyralux ${ }^{\circledR} \mathrm{AC}$ with a copper conductive pattern and without the surface finish (hereinafter referred to as "FPCB Cu"). The third type was the flexible printed circuit board MELINEX ${ }^{\circledR}$ ST504 with a silver conductive pattern DuPont 5064H (hereinafter referred to as "FPCB Ag"). On all of them, a conductive pattern for the gluing of ten SMD chip components was made on one side (see Fig. 2).

For the experiment, three different SMD chip with resistors of negligible value having package sizes 1206 , 0805 and 0603 with the tin surface finished contacts were used (see Fig. 3).

Two different electrically conductive adhesives with silver flakes were selected for the experiment. The first adhesive's brand name was "EPO-TEK®H20S" and this is produced by the Epoxy technology Inc. The particle size of silver flakes in this adhesive is less than $20 \mu \mathrm{m}$ and the adhesive has a resistivity $0.0005 \Omega \mathrm{cm}$. The price of this adhesive is approximately 3 times higher than the 


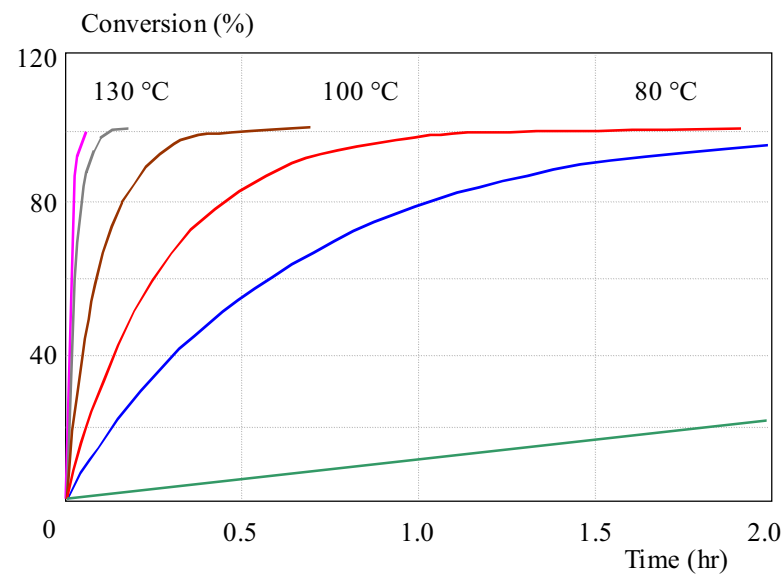

Fig. 4. Dependence of percent conversion on temperature and time of curing for adhesive $8331 \mathrm{~S}$, with E: $54.6 \mathrm{~kJ} / \mathrm{mole} \pm 2.08 \%$, log Z: $6.881 / \mathrm{min} \pm 2.32 \%$, 60 min half-life: 51.6 Cels, Enthalpy: 55.5 $\mathrm{J} / \mathrm{g} \pm 24.67 \%$

Table 1. Size of the pads in pattern for all components

\begin{tabular}{cccc}
\hline Size of the component & 1206 & 0805 & 0603 \\
Width & $1.4 \mathrm{~mm}$ & $0.7 \mathrm{~mm}$ & $0.5 \mathrm{~mm}$ \\
Length & $1.6 \mathrm{~mm}$ & $1.3 \mathrm{~mm}$ & $0.9 \mathrm{~mm}$ \\
\hline
\end{tabular}

Table 2. The parameters of used stencils and ratio amount of the adhesives

\begin{tabular}{cccc}
\hline Thickness of stencil & $120 \mu \mathrm{m}$ & $120 \mu \mathrm{m}$ & $80 \mu \mathrm{m}$ \\
Reduction of width and length & $5 \%$ & $20 \%$ & $20 \%$ \\
Ratio amount & $100 \%$ & $71 \%$ & $47 \%$ \\
\hline
\end{tabular}

Table 3. The curing profiles of the electrically conductive adhesives

\begin{tabular}{ccc}
\hline Type of adhesive & Curing temperature & Curing time \\
\hline \multirow{2}{*}{ EPO-TEK ${ }^{\circledR} \mathrm{H} 2 \mathrm{Os}$} & $120^{\circ} \mathrm{C}$ & 15 minutes \\
\hline \multirow{2}{*}{$\mathrm{MG} \mathrm{8331S}$} & $135^{\circ} \mathrm{C}$ & 15 minutes \\
\hline
\end{tabular}

price of the 8331S adhesive. The adhesive $\mathrm{H} 20 \mathrm{~S}$ has five recommended curing profiles from $80{ }^{\circ} \mathrm{C}$ per 90 minutes to $175^{\circ} \mathrm{C}$ per 45 seconds. The second adhesive's brand name is "8331S" and this is produced by M.G. Chemicals Ltd. This adhesive has a resistivity $0.0060 \Omega \mathrm{cm}$. The adhesive has four recommend curing profiles from $25^{\circ} \mathrm{C}$ per 96 hours to $100{ }^{\circ} \mathrm{C}$ per 50 minutes. Both of these named adhesives are two-component and can be stored at room temperature. Storage in a freezer is not recommended or required; this represents an opportunity to reduce costs; these adhesives do not require cooling.

Stencil printing was used to apply the electrically conductive adhesives onto the printed circuit boards. For the experiment, three different volumes of the adhesive were used (see Table 2). The reduction of width and length meant that the holes in the stencils were reduced by about $5 \%$ and $20 \%$ in width and in length due to the pads in the conductive patterns on the PCBs. The pads in these patterns are standardized (see Table 1).

The samples were weighed by the analytical balance Kern ALJ 120-4 and by the analytical laboratory balance Radwag XA 52/2X. The weight of one joint was then calculated.

Better results with curing profiles different from the datasheet were found for the adhesive 8331S in previous experiments. For this reason a DSC analysis for this adhesive was performed. This analysis, "Differential Scanning Calorimetry", was performed using a SDT Q600 thermal analyzer (TA Instruments). The DSC analysis can be used for the determination of curing degree dependence on curing time and curing temperature. The results of this analysis can be seen in Fig. 4.

The best profiles from the datasheets $100^{\circ} \mathrm{C} / 50 \mathrm{~min}$ (8331S), $120^{\circ} \mathrm{C} / 15 \mathrm{~min}(\mathrm{H} 20 \mathrm{~S})$ found in previous experiments (eg [10]) were used for this experiment. Moreover, the profile $135^{\circ} \mathrm{C} / 15 \mathrm{~min}(\mathrm{H} 20 \mathrm{~S})$ was found by long experience with this adhesive to be the best. In addition, the profile $130{ }^{\circ} \mathrm{C} / 30$ min was defined by DSC analysis with the following assumptions. The first assumption was that the higher curing temperature will improve the mechanical strength of a joint and reduce the time for curing. The second assumption was manifested in the use of the adhesive on flexible substrates which usually have maximal allowable temperature of under $150{ }^{\circ} \mathrm{C}$; the assumption being that the substrates could endure the temperature which was chosen. All used profiles are stated in Table 3.

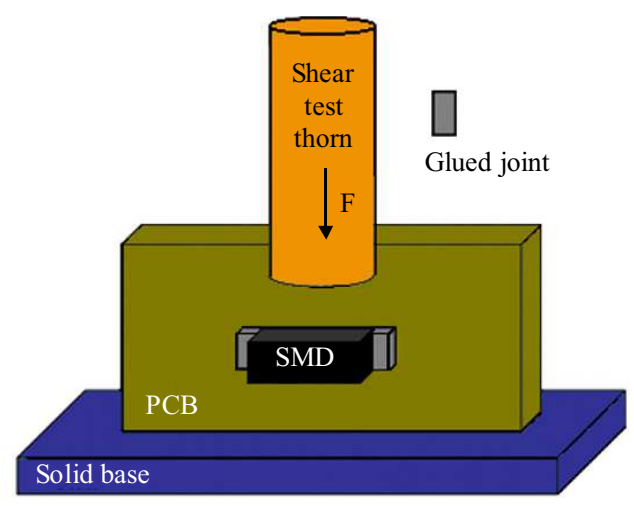

Fig. 5. The principle of the shear strength test

The laboratory drying oven Heraeus 5050 was used for curing the adhesives. The temperature inside the drying oven was measured by a measuring preparation made at the Department of Technologies and Measurement. This preparation was connected to the multimeter METRAHIT from the Gossen Metrawatt Company. This multimeter was connected to the computer and the profiles were recorded by the software LabVIEW from the National Instruments Company.

The mechanical shear strength of the adhesive joint was measured for each sample. The flexible PCB samples were glued to the rigid PCB before testing because the samples were flexible. The principal of the mechanical 


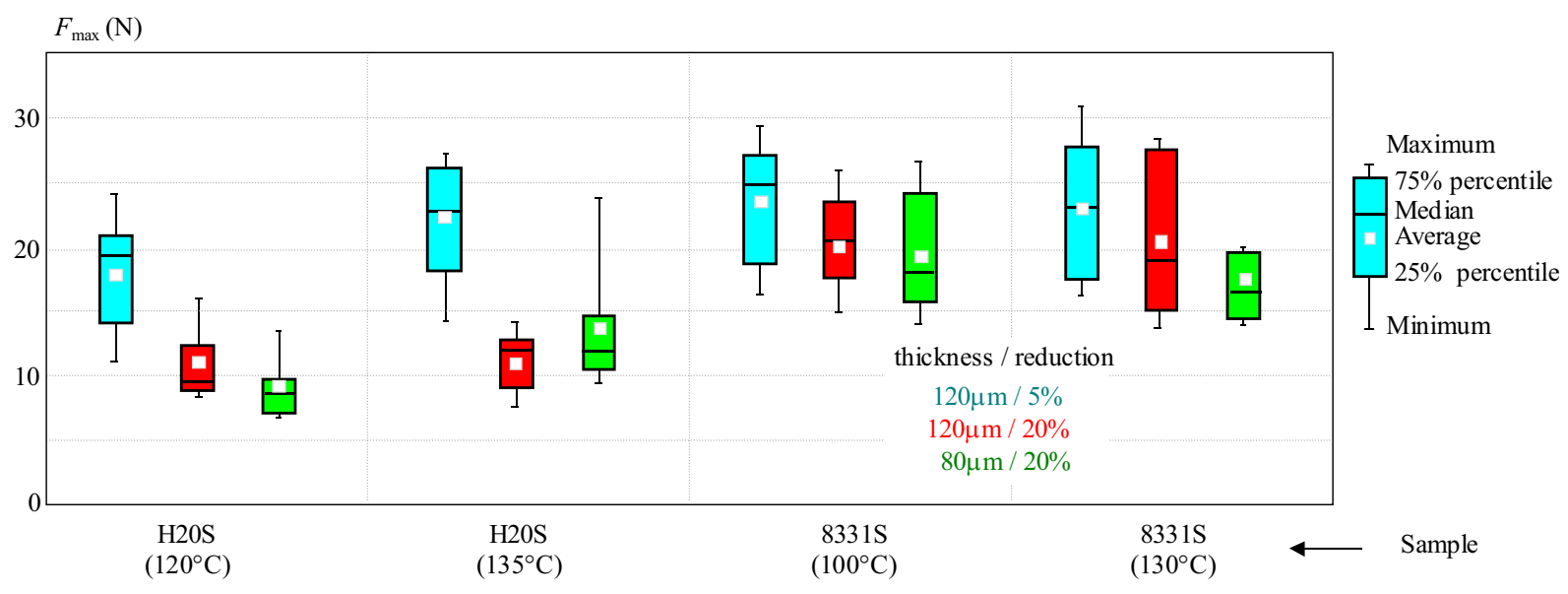

Fig. 6. Example of boxplot of maximal force when shearing-off 1206 chip resistors glued on FPCB Ag

shear strength test can be seen in Fig. 5. The thorn pushes with force onto the component until the disruption of the joint, and the shear-off of the component from the PCB. The shear strength of the joint was not measured directly because the surface under load is not known. The maximal force used during the test was recorded. The device LabTest 3.030 was used for the recording of the force acting on the chip resistor. The settings of the device were as follows: feed rate of shear thorn $-20 \mathrm{~mm} / \mathrm{min}$, jaws return $200 \mathrm{~mm} / \mathrm{min}$, criterion of test end - when $50 \%$ of maximal force $\left(F_{\max }\right)$ was reached. Ten components were measured for each sample and ten values of maximal force were statistically analyzed for each sample. The statistical analysis was performed by calculation of arithmetical mean, $25 \%$ percentile, $50 \%$ percentile (median) and $75 \%$ percentile. This values with maximal and minimal measured values were used for creation of the boxplot diagrams.

\section{RESULTS AND DISCUSSION}

The maximal force required to shear off the component from the $\mathrm{PCB}$ was recorded each time the mechanical shear strength test was performed. The recorded values were statistically analyzed and an example of the results of these analyses can be seen in Fig. 6 .

For our experiment, a method called "Design of Experiments" (DOE) (eg [14]) was applied, and for the evaluation of the experimental results, factor analysis $(e g[15,16])$ was applied. This analysis investigates the influence of input factors on the values of output factors. Factor analysis is used for the evaluation of results in this article. This method is often used for the detection of more and less significant factors, eg [14]. This analysis should answer to the next questions and the defined hypothesis. This hypothesis is that influence of component size on the mechanical shear strength is large. The first question, what is influence of curing profile on the mechanical shear strength? The second question, what is large difference between the mechanical shear strength of adhesive components on rigid substrate and on the flexible substrate? The third question, what is influence of adhesive amount on the mechanical shear strength? The fourth question, what is influence of adhesive type on the mechanical shear strength? The results of this analysis and answers to the questions are seen in Fig. 7 .

The defined hypothesis was approved, it means that the influence of component size on the mechanical shear strength is large and it is significant factor. The first answer, the influence of curing profile on the mechanical shear strength is visible and from the experiment follows that the definition of the new profile could improve the mechanical shear strength. The second answer, large difference between the mechanical shear strength of adhesive components on rigid substrate and on the flexible substrate is visible but difference between the mechanical shear strength of adhesive components on the first flexible substrate and on the second flexible substrate is insignificant. The third answer, the influence of adhesive amount on the mechanical shear strength is visible, significant and the reduction of adhesive amount from $100 \%$ to $71 \%$ is more significant than reduction from $71 \%$ to $47 \%$. The fourth answer, the influence of adhesive type on the mechanical shear strength is visible but it is insignificant.

The samples were also looked at via microscopic observation after the test and some typical results of this observation can be seen in Figs. 8 and 9. The separation of the conductive pattern from the substrate is seen in Fig. 8. This separation is caused by the production procedures and the properties of the substrate. The cohesive fracture of the joint using "EPO-TEK $(\mathrm{H} 20 \mathrm{~S}$ " is seen in Fig. 9(a). The adhesive fracture of the joint using "MG 8331" is seen in Fig. 9(b).

Metallographic cross-sections were important for providing additional information about the structure of the glued joints and the interface between joint and conductive pattern. These metallographic cross-sections can be scanned using a laser confocal microscope (LEXT) (eg [17]), a fluorescence microscope or an electron microscope. 

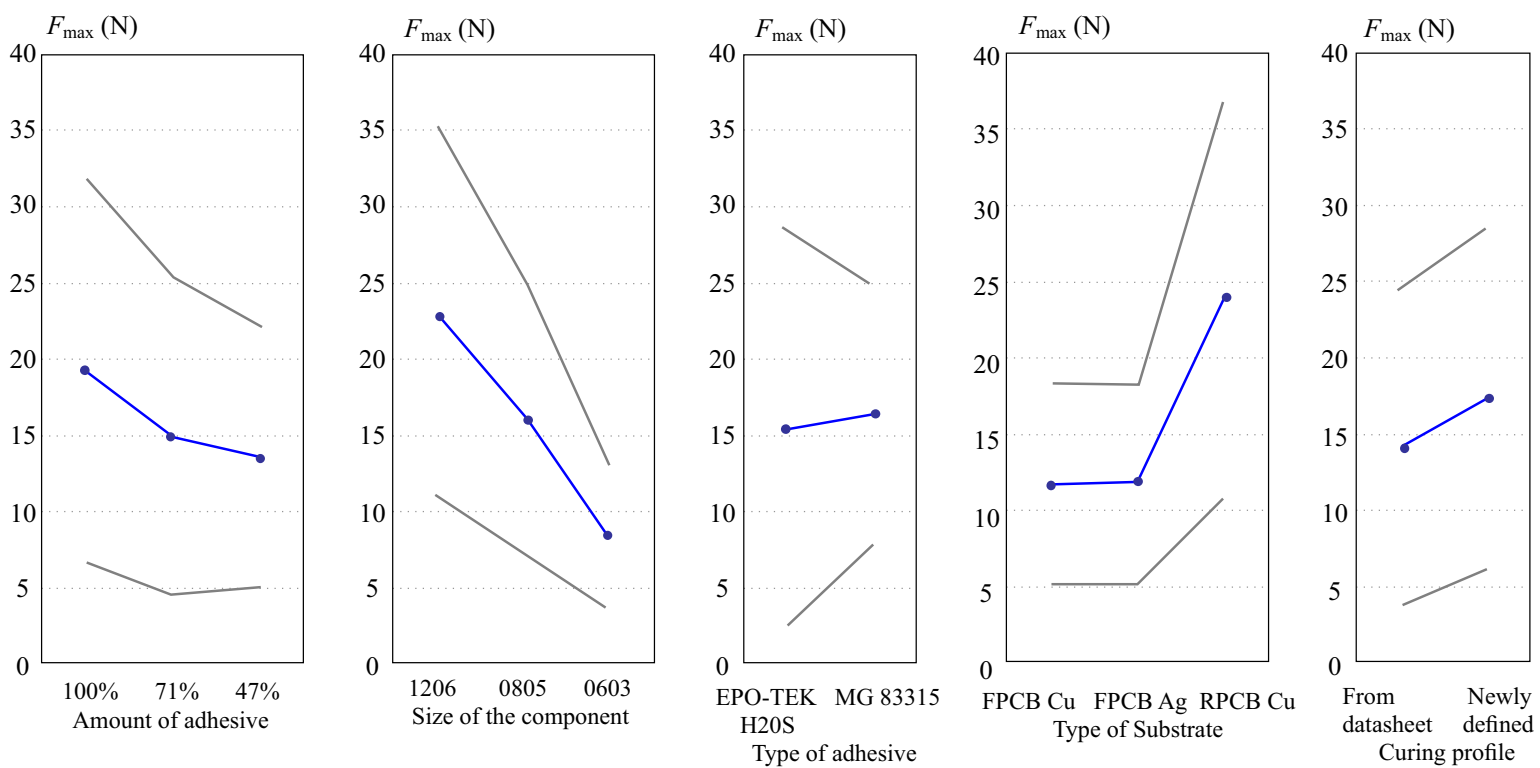

Fig. 7. Influence of factors on the mechanical shear strength from DOE methodology

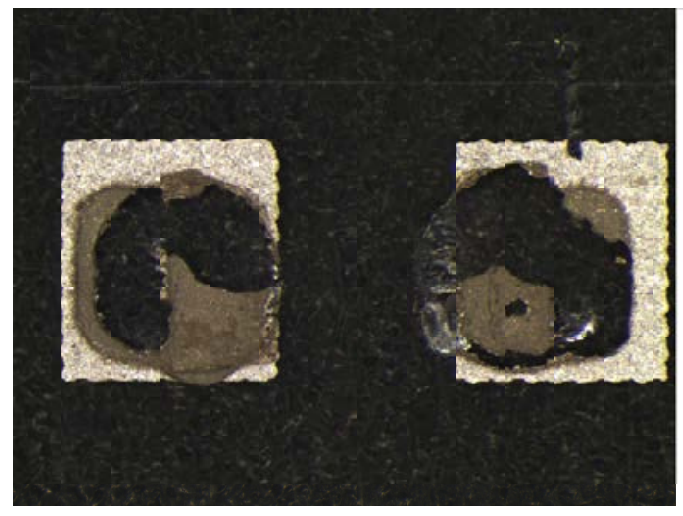

(a)

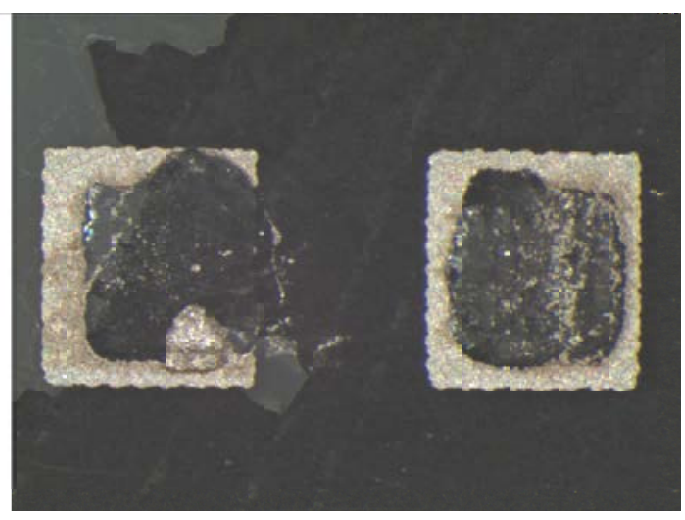

(b)

Fig. 8. Detail of the joint glued on the FPCB Ag (a) - by EPO-TEK@ H20S and, (b) - by MG 8331S

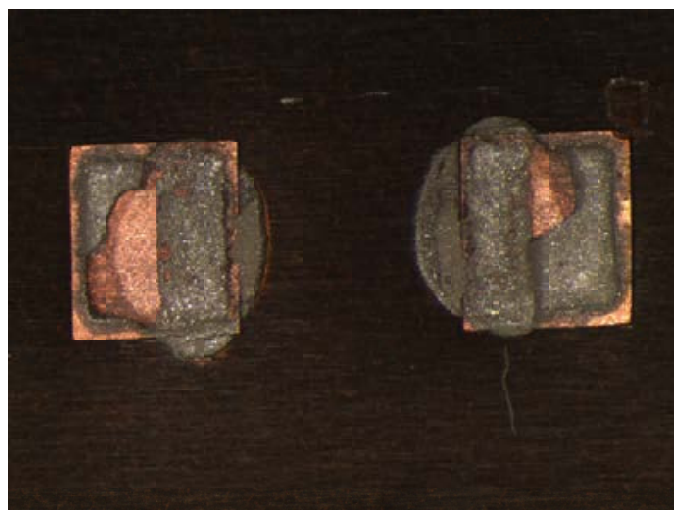

(a)

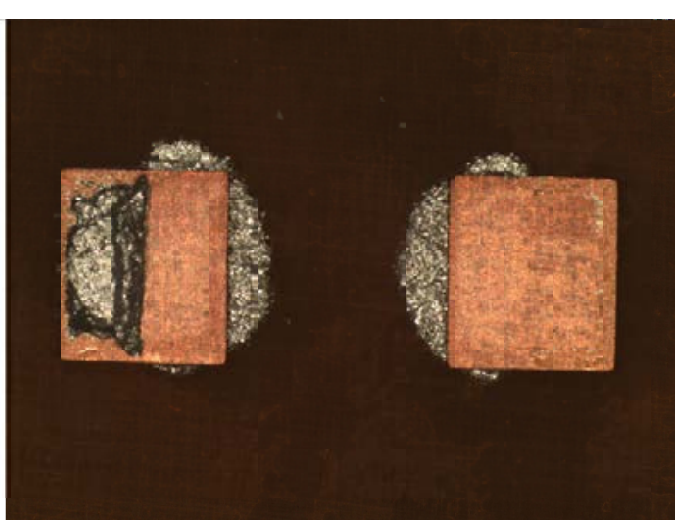

(b)

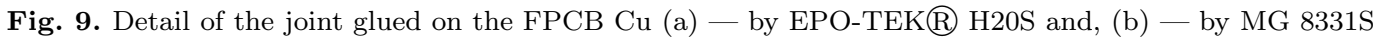

Metallographic cross-sections of samples were made for RPCB and FPCB Ag and for each adhesive (4 crosssections). These cross-sections were observed by laser confocal microscope (LEXT). In Fig. 10 the broken adhesive joint on rigid substrates including adhesion fracture between component and adhesive can be seen. The size and shape of the particles in the adhesives can be also seen.
In Fig. 11 the electrically conductive adhesive joint on flexible substrates can be seen.

In order to gather additional information, the crosssections of samples on FPCB Ag were observed using a fluorescence microscopy, see Fig. 12. This type of microscopy was used for better fracture analysis. The cohesion fracture between conductive pattern and flexible 


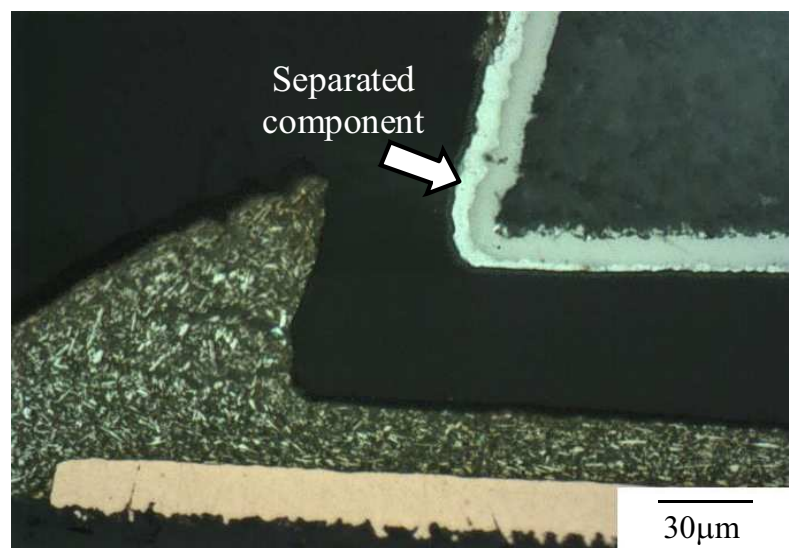

(a)

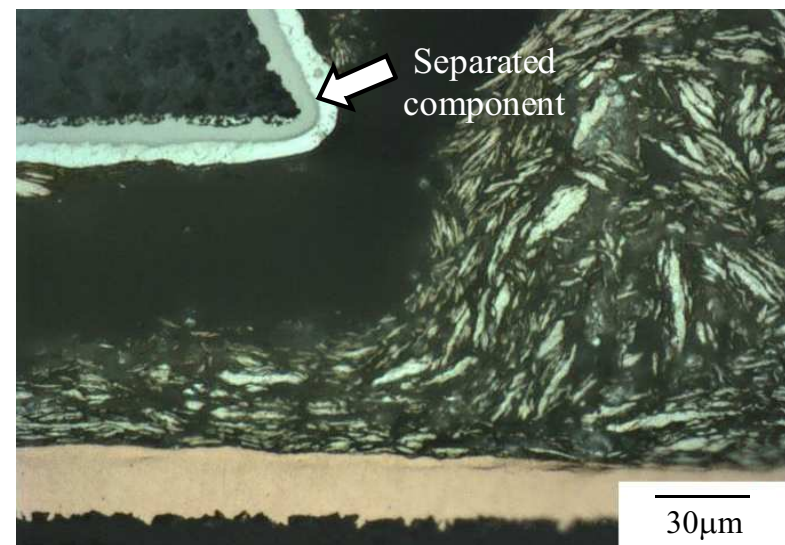

(b)

Fig. 10. Detail of cross-sections of samples on RPCB from LEXT microscope (a) — glued by EPO-TEK® H20S and, (b) — by MG $8331 \mathrm{~S}$

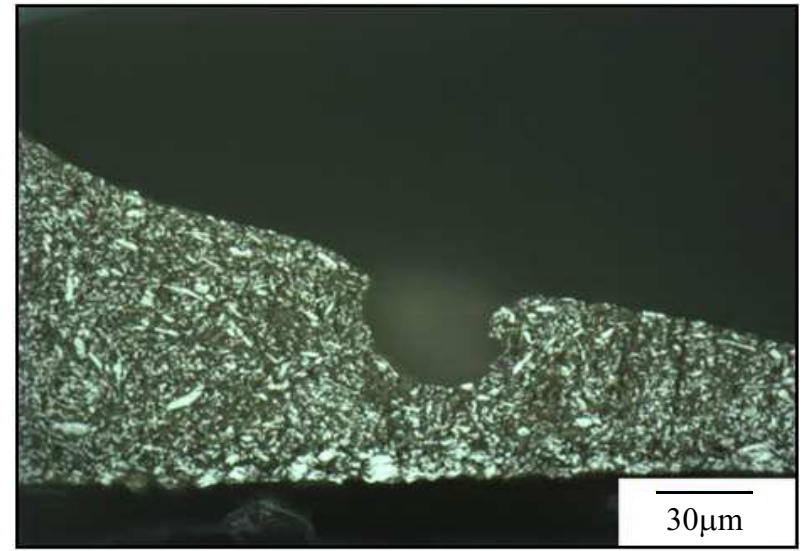

(a)

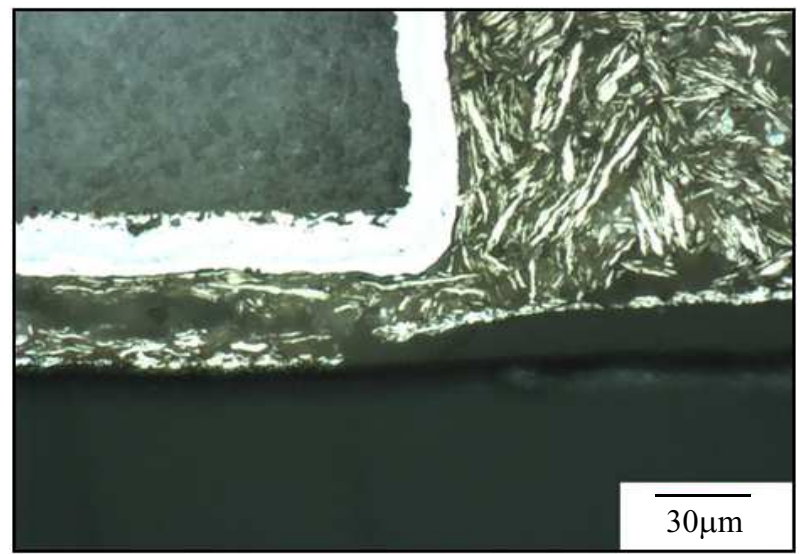

(b)

Fig. 11. Detail of cross-sections of samples from LEXT microscope on FPCB Ag (a) — glued by EPO-TEK® H20S and, (b) — by MG $8331 \mathrm{~S}$

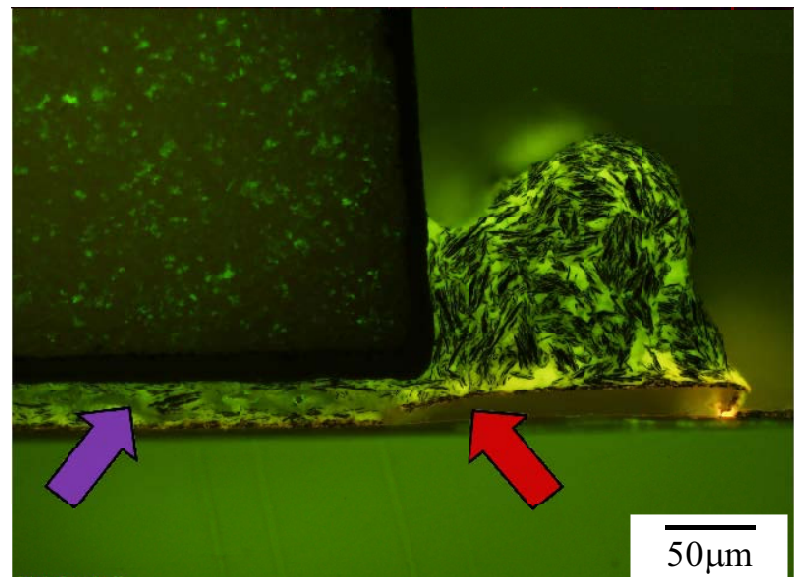

(a)

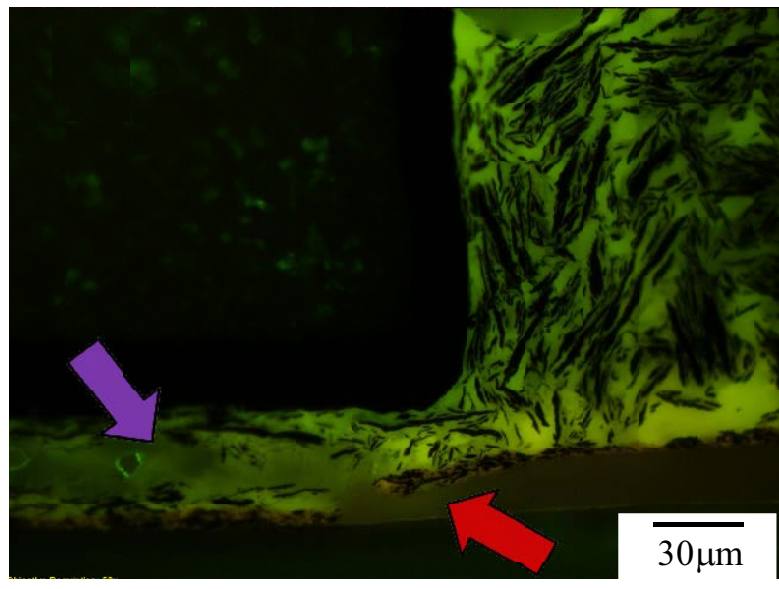

(b)

Fig. 12. Electrically condutive adhesive MG 8331S on FPCB Ag

material can be seen in the right part of both images (red arrows) and the fracture in the adhesive can be seen in left part of the both images (purple arrows) in this figure.

These cross-sections were observed using a scanning electron microscope (SEM). An energy dispersive x-ray analysis (EDX) was performed for the detection of the material structure of samples in chosen test spots, see Figure 13, Table 4 and Figure 14, Table 5.

Oxygen in the material structure was caused by the oxidation of metals in air. Other elements in tested spots were not found. It follows that all materials used were 


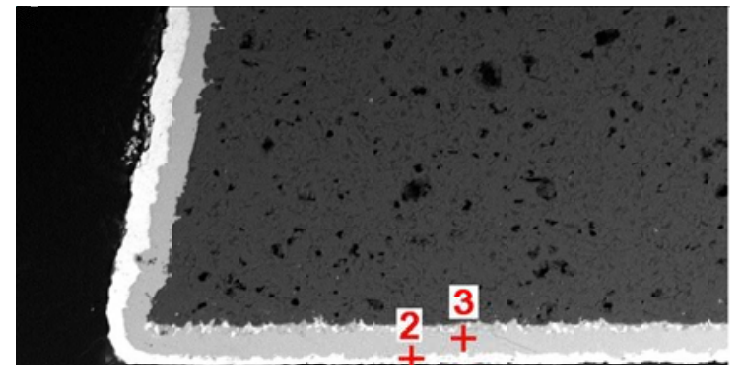

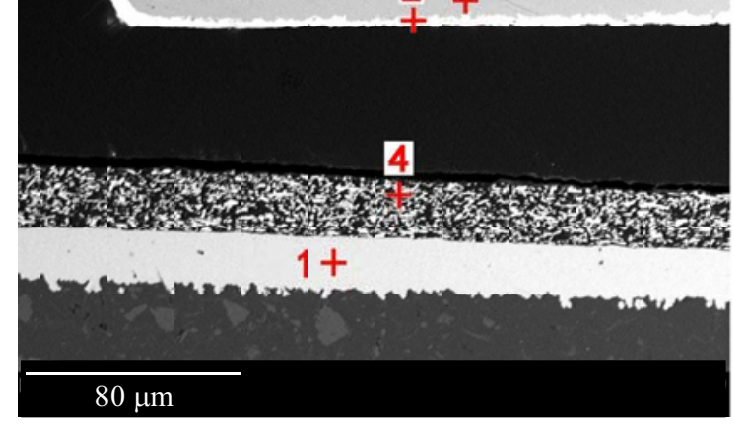

(a)

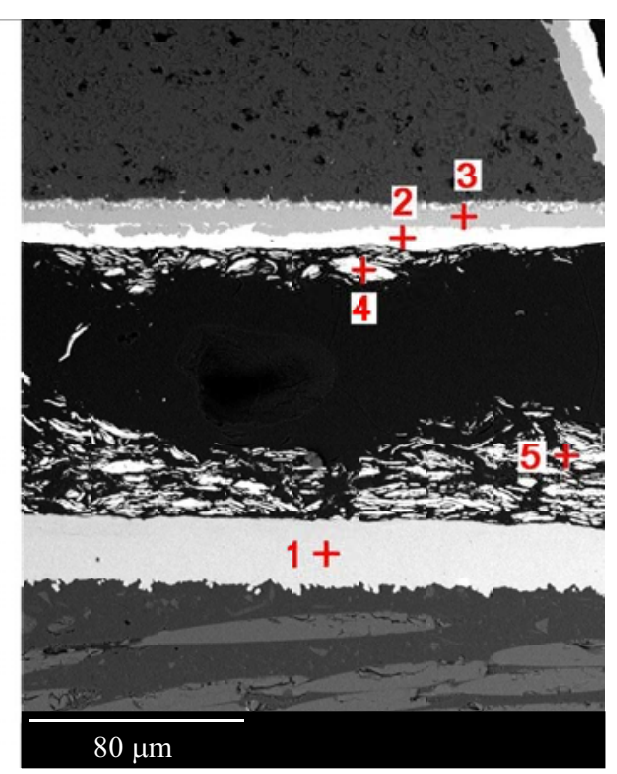

(b)

Fig. 13. Detail of cross-sections of samples with marked test spots from SEM - EDX on RPCB (a) - glued by EPO-TEK H20S and, (b) - by MG $8331 \mathrm{~S}$

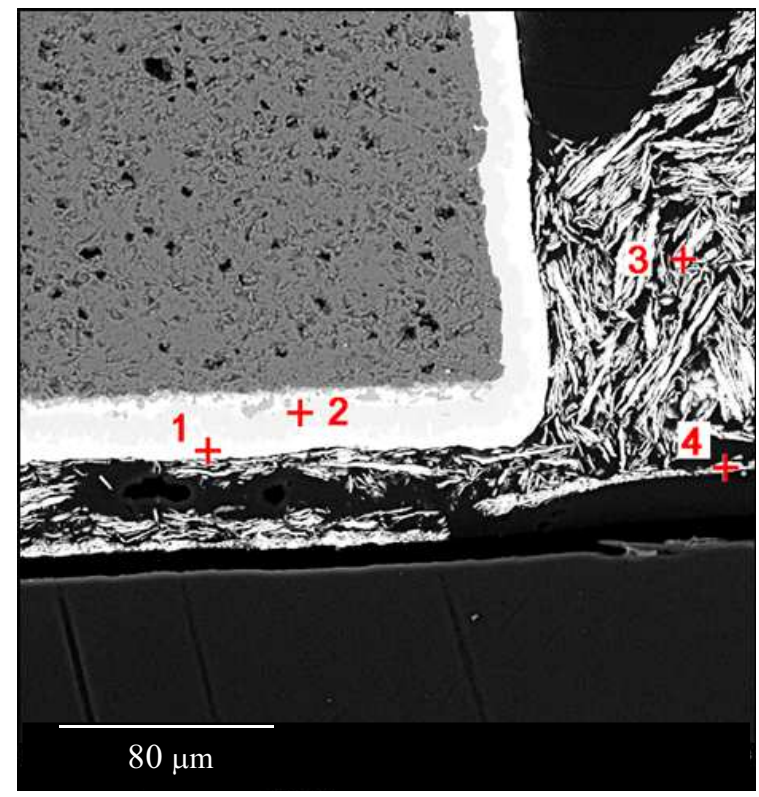

Fig. 14. Detail of cross-sections of samples with marked test spots from SEM-EDX on FPCB Ag glued by MG 8331S

pure and did not contain any intermetallic compounds or additives.

\section{CONCLUSION}

The experiment provided proof of the impact of electrically conductive adhesive quantity on the shear strength of glued joints on flexible substrates only. In general, the electrically conductive adhesive "MG 8331S" seemed to be the better choice for use on flexible substrates in terms of mechanical shear strength of joint. The electrically conductive adhesive "EPO-TEK®H20S" seemed to be the better choice for use on rigid substrates in terms of mechanical shear strength of joint, but the adhesive "8331S" is more economical. The results show that increases in conductive pattern roughness ensure greater mechanical shear strength. As already mentioned, the samples with adhesive "8331S" on FPCB $\mathrm{Cu}$ show adhesive fracture between the conductive pattern and the conductive adhesive. This fact points to an opportunity for further experiments and for the improvement of mechanical shear strength by roughening the copper conductive pattern. The results also show that newly designed curing profiles increased the mechanical shear strength of joints, but the question is whether these profiles have worse properties after ageing and/or worse electrical properties. The difference between results on rigid PCB and both flexible $\mathrm{PCB}$ is large it follows that general conclusions for using of adhesive on rigid $\mathrm{PCB}$ is impossible to use for flexible PCB and using of adhesives on flexible PCB have to be researched further.

Table 4. Material structure of sample glued by EPO-TEK(R)H20S adhesive and by MG 8331S adhesive on RPCB

\begin{tabular}{|c|c|c|c|c|c|c|}
\hline \multicolumn{4}{|c|}{ EPO-TEK(R) H20S } & \multicolumn{3}{|c|}{ MG 8331S } \\
\hline $\begin{array}{c}\text { Spot } \\
\mathrm{Nr} .\end{array}$ & $\begin{array}{r}\text { Eler } \\
\text { Symbol }\end{array}$ & $\begin{array}{l}\text { ment } \\
\text { Name }\end{array}$ & $\begin{array}{c}\text { Atomic } \\
\text { Concen- } \\
\text { tration }\end{array}$ & $\begin{array}{c}\text { Elem } \\
\text { Symbol }\end{array}$ & $\begin{array}{l}\text { nent } \\
\text { Name }\end{array}$ & $\begin{array}{c}\text { Atomic } \\
\text { Concen- } \\
\text { tration }\end{array}$ \\
\hline 1 & $\mathrm{Cu}$ & Copper & $100 \%$ & $\mathrm{Cu}$ & Copper & $100 \%$ \\
\hline 2 & $\begin{array}{c}\mathrm{O} \\
\mathrm{Sn}\end{array}$ & $\begin{array}{c}\text { Oxygen } \\
\text { Tin }\end{array}$ & $\begin{array}{l}65.1 \% \\
34.9 \% \\
\end{array}$ & $\mathrm{Sn}$ & $\operatorname{Tin}$ & $100 \%$ \\
\hline 3 & $\begin{array}{c}\mathrm{Ni} \\
\mathrm{O}\end{array}$ & $\begin{array}{c}\text { Nickel } \\
\text { Oxygen }\end{array}$ & $\begin{array}{c}90.3 \% \\
9.7 \%\end{array}$ & $\mathrm{Ni}$ & Nickel & $100 \%$ \\
\hline 4 & $\begin{array}{c}\mathrm{Ag} \\
\mathrm{O}\end{array}$ & $\begin{array}{c}\text { Silver } \\
\text { Oxygen }\end{array}$ & $\begin{array}{l}44.9 \% \\
55.1 \%\end{array}$ & $\mathrm{Ag}$ & Silver & $100 \%$ \\
\hline 5 & & & & $\mathrm{Ag}$ & Silver & $100 \%$ \\
\hline
\end{tabular}


Table 5. Material structure of sample glued by "MG 8331S" adhesive on FPCB Ag

\begin{tabular}{cccc}
\hline Spot & \multicolumn{2}{c}{ Element } & Atomic \\
Nr. & Symbol & Name & Concentration \\
\hline \multirow{2}{*}{1} & $\mathrm{Sn}$ & Tin & $41.8 \%$ \\
& $\mathrm{O}$ & Oxygen & $58.2 \%$ \\
\hline \multirow{2}{*}{2} & $\mathrm{Ni}$ & Nickel & $78.8 \%$ \\
& $\mathrm{O}$ & Oxygen & $21.2 \%$ \\
\hline \multirow{2}{*}{3} & $\mathrm{Ag}$ & Silver & $52.1 \%$ \\
& $\mathrm{O}$ & Oxygen & $47.9 \%$ \\
\hline \multirow{2}{*}{4} & $\mathrm{O}$ & Oxygen & $56.6 \%$ \\
& $\mathrm{Ag}$ & Silver & $43.4 \%$ \\
\hline
\end{tabular}

\section{Acknowledgement}

This research has been supported by the Ministry of Education, Youth and Sports of the Czech Republic under the RICE - New Technologies and Concepts for Smart Industrial Systems, project No. LO1607 and by the Student Grant Agency of the University of West Bohemia in Pilsen, grant No. SGS-2015-020 "Technology and Materials Systems in Electrical Engineering".

\section{REFERENCES}

[1] Directive 2011/65/EU of the European Parliament and of the Council on the Restriction of the Use of Certain Hazardous Substances in Electrical and Electronic Equipment (RoHS), 2011 http://eur-lex.europa.eu/ legal-content/EN/TXT/?uri=CELEX:32011L0065.

[2] Directive 2012/19/EU of the European Parliament and of the Council on Waste Electrical and Electronic Equipment (WEEE), 2012, http://eur-lex.europa.eu/ legal-content/EN/TXT/?uri=CELEX:32012L0019..

[3] KUBERSKÝ, P.-SYROVÝ, T.-HAMÁČEK, A-NEŠPŮREK, S.-STEJSKAL, J. : Printed Flexible Gas Sensors based on Organic Materials, Procedia Eng. 120 (2015), 614-617.

[4] MACH, P.-DURAJ, A.-BUŠEK, D.-DUŠEK, K. : Influence of Combined Ageing on Resistance and Noise of Electrically Conductive Adhesive Joints, 1st Int. Microelectron. Assem. Packag. Soc. Flash Conf., 2015, pp. 42-43.

[5] ZHANG, R.-AGAR, J. C.-WONG, C. P.: Recent Advances on Electrically Conductive Adhesives, 12th Electron. Packag. Technol. Conf. no. c, 2010, pp. 696-704.

[6] BARTO, S.-CINERT, J.-MACH, P.: Influence of Thermal Aging on the Reliability of Electrically Conductive Adhesives, 2011 IEEE 17th Int. Symp. Des. Technol. Electron. Packag., 2011, pp. 305-308.

[7] WICKHAM, M.-ZOU, L.-HUNT, C.: Measuring the Effect of Substrate and Component Finishes on the Reliability of Isotropic Electrically Conductive Adhesive Joints, Solder. Surf. Mt. Technol. 21 No. 4 (Sep 2009), 12-18.

[8] PODZEMSKY, J.-URBANEK, J.-DUSEK, K. : Shear Strength of Joints Made of Lead-Free Solders, in Proceedings of the 2011 34th International Spring Seminar on Electronics Technology (ISSE), 2011, pp. 84-88.
[9] OCKLEnBuRG, J.-RASTJAGAEV, E.-WILDE, J.: Investigation of Modern Electrically Conductive Adhesives for Die-Attachment in Power Electronics Applications, Electron. Components Technol. Conf. (ECTC 2013), 2013, pp. 2189-2195.

[10] HIRMAN, M.-STEINER, F.: A Comparison of the Shear Strength of Conductive Adhesives and Soldering Alloys, in Proceedings of the 38th International Spring Seminar on Electronics Technology, 2015.

[11] DUSEK, K.-BUSEK, D.-BERAN, T.-RUDAJEVOVA, A. : Comparison of Shear Strength of Soldered SMD Resistors for Various Solder Alloysinbook in the 38th International Spring Seminar on Electronics Technology (ISSE).

[12] Object Management Group Inc., Methodology Business Process Model and Notation (BPMN 2.0), 2015, http://www.bpmn.org/.

[13] POPESCU, R.-STAIKOPOULOS, A.-LIU, P.—BROGI, A. - CLARKE, S.: Taxonomy-Driven Adaptation of Multi-layer Applications using Templates, in 2010 Fourth IEEE International Conference on Self-Adaptive and Self-Organizing Systems, 2010, pp. 213-222.

[14] GU, Y.--JIN, D. : Drop Test Simulation and DOE Analysis for Design Optimization of Microelectronics Packages, Proc. Electron. Components Technol. Conf., vol. 2006, 2006, pp. 422-427.

[15] KOSIBA, R.-ECKE, G.-LIDAY, J.-BREZA, J.-AMBACHER, O.: Auger Depth Profiling and Factor Analysis of Sputter Induced Altered Layers in SiC, J. Electr. Eng. 54 No. 01-02 (2003), 52-56.

[16] LiDAY, J.-CATAROVA, M.-MATUSKOVA, E.-KOSIBA, R.-ECKE, G.-VOGRINCIC, P.-BREZA, J. : Quantitative Aufer Depth Profiling of Ni/C Multilayers by Factor Analysis and Comparison with T-Dyn Simulations, J. Electr. Eng. 52 No. 05-06 (2001), 162-165.

[17] STEINER, F.-RENDL, K.-WIRTH, V.: Correlation Analysis of Wettability, Intermetallic Compound Formation and PCB Contamination, Circuit World 41 No. 2 (May 2015), 70-75.

Received 25 March 2015

Martin Hirman was born in Pilsen in 1989. He is a PhD student at the Department of Technologies and Measurement of the University of West Bohemia in Pilsen. He graduated from the University of West Bohemia and holds a master's degree in in the field of commercial electrical engineering (awarded in 2013). The topic of his doctoral thesis is "Diagnostics of components and substrates interconnection". His research interests focus on "electrically conductive adhesives especially in regard to flexible substrates".

Frantisek Steiner was born in Rokycany in 1973. He was awarded an Ing (MSc) degree in the field of Applied Electronics in 1996, a PhD in the field of Electronics in 2001 and an Associate Professorship in Electrical Engineering in 2008. He is Associate Professor at the Faculty of Electrical Engineering of the University of West Bohemia. He is head of the Section of Industrial Process Control. He is also head of the Diagnostics and Testing Engineering Team at The Regional Innovation Centre for Electrical Engineering (RICE). His research fields include diagnostics of electronic assemblies, soldering, replacement of lead based solder and intermetallic compounds. He has published more than 101 papers and presented 32 contributions in 29 congresses. 